\title{
PAPERS
}

\section{Oral theophylline in chronic heart failure}

\author{
S. Al-Damluji \\ B.Sc., M.R.C.P. \\ A. JoHNSTON \\ B.Sc. \\ R. A. J. SPURRELL \\ M.D., F.R.C.P.
}

\author{
A. W. Nathan \\ M.B., M.R.C.P. \\ S. O. BANIM \\ M.B., M.R.C.P.
}

\author{
A. J. CAMM \\ B.Sc., M.R.C.P.
}

Department of Cardiology, St Bartholomew's Hospital, London E.C.1

\begin{abstract}
Summary
Theophylline choline $600 \mathrm{mg}$ was given as a single oral dose to nine patients in chronic left ventricular failure due to myocardial dysfunction. Cardiac output, left ventricular filling pressure (LVFP) and right atrial pressure (RAP) were measured with a pulmonary artery thermodilution catheter for the following $3 \mathrm{hr}$. Continuous recordings of cardiac rhythm were made throughout the study. Mean cardiac index increased from $1.75( \pm 0.14$ s.e. mean) to $2.04( \pm 0 \cdot 11) 1 / \mathrm{min} / \mathrm{m}^{2}(P<0.02)$, mean LVFP fell from $27( \pm 2.4)$ to $22( \pm 1.5) \mathrm{mmHg}(P<0.01)$, mean RAP fell from $5( \pm 1 \cdot 3)$ to $3( \pm 2 \cdot 0) \mathrm{mmHg}(P$ $<0.05)$ and mean systemic arterial pressure rose from $80( \pm 3)$ to $86( \pm 3.5) \mathrm{mmHg}(P<0.05)$. There were no significant changes in heart rate or systemic vascular resistance; thus the increase in cardiac output was probably due to a positive inotropic effect. Side effects were seen in two patients, both of whom proved to have toxic plasma theophylline concentrations.

This study demonstrated a beneficial acute haemodynamic effect of oral theophylline in chronic cardiac failure.

\section{Introduction}

In patients with severe chronic heart failure resistant to diuretics there is a need for additional oral agents capable of improving cardiac haemodynamics. Such agents include hydralazine which reduces afterload (Fitchet et al., 1979), isosorbide dinitrate which reduces preload (Williams et al., 1977), and salbutamol which may increase cardiac output by a mixture of afterload reduction and positive inotropism (Sharma and Goodwin, 1978).
\end{abstract}

Intravenous infusions of theophylline (and its derivative aminophylline) are known to increase cardiac output in patients in heart failure (Howarth, McMichael and Sharpey-Schafer, 1947; Parker Kelly and West, 1966). This is predominantlp through a positive inotropic effect (Murphy Schreiner and $\mathrm{Yu}, 1968)$, although a periphera vasodilator action has also been suggested (Parker et al., 1966). As there are now long-acting oral preparations of theophylline, this drug may be a useful addition to the agents already in use in the treatment of refractory chronic heart failure. However, there are no reported studies on the haemodynamic effects of theophylline or aminophylline given orally in chronic left ventricular failure.

The aim of this study was to assess the haemodynamic effects of a single, rapidly absorbed oral dose of theophylline and to identify possible side effects in relation to plasma theophylline concentrations.

\section{Patients and methods}

Nine men were studied (Table 1). Their heart failure was due to myocardial dysfunction rather than valvular pathology, as determined by cardiac catheterization or echocardiography. The patients were all refractory to diuretics and had been admitted for stabilization of heart failure. The insertion of a pulmonary artery catheter formed part of their routine management. All gave informed consent to the study. None had a history suggestive of airways obstruction.

Theophylline choline $600 \mathrm{mg}$ (Choledyl ${ }^{\circledR}$, William R. Warner \& Company Ltd) was given as a single 


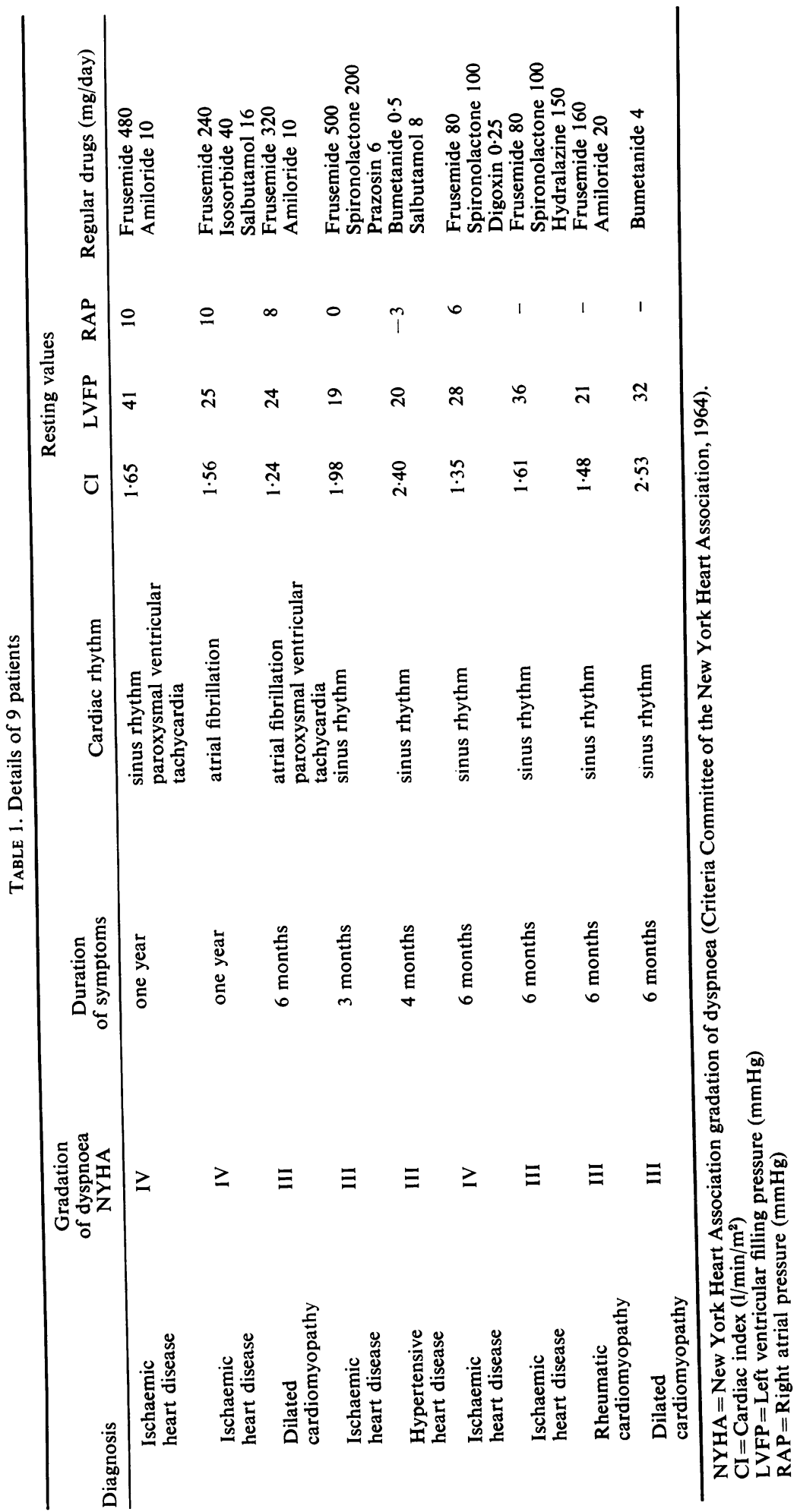




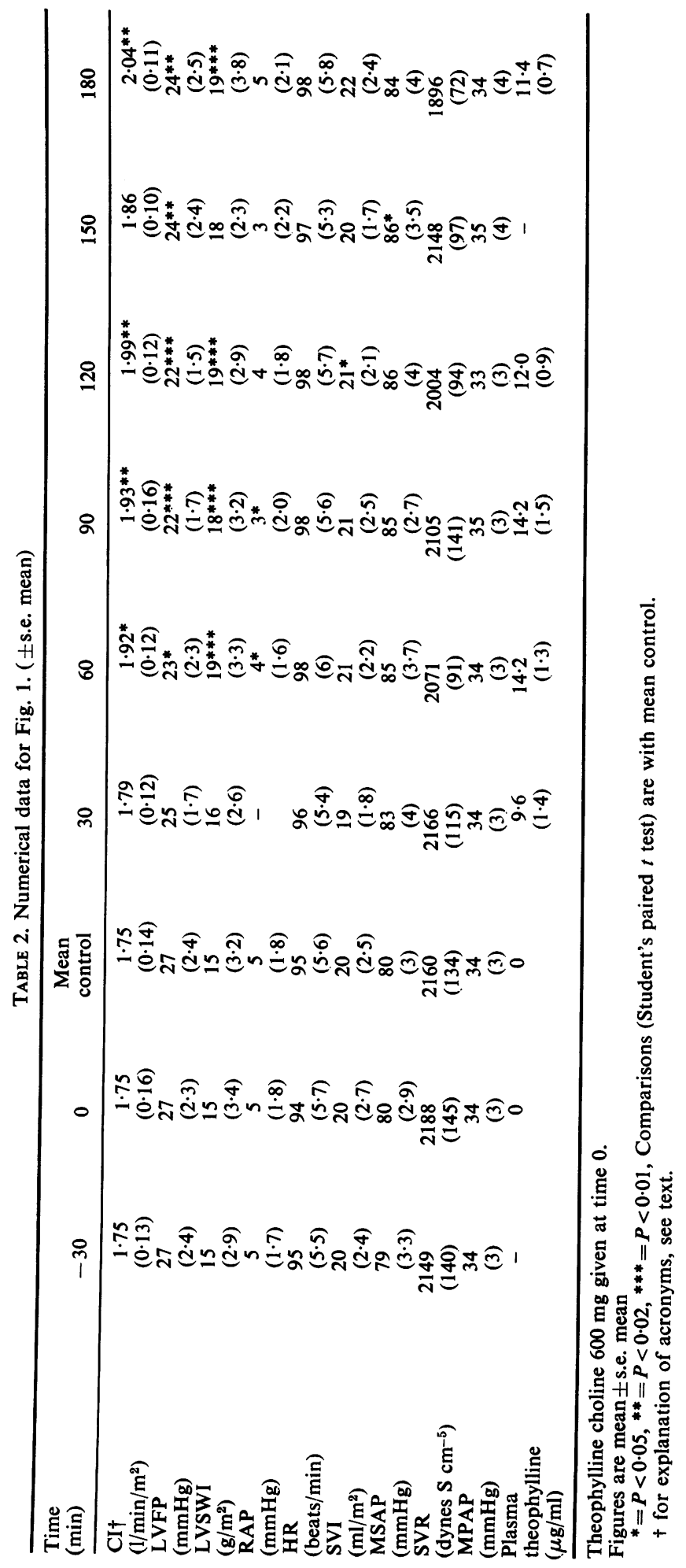


oral dose. This preparation was chosen because it is rapidly absorbed. In chronic asthmatics it reaches a peak plasma concentration within one hour and has half-life of 6 hours (Jones, 1979).

The patients were specifically questioned at 30min intervals about nausea, tremor, headaches and chest pain.

Blood samples were taken immediately before the drug was given and at 30-min intervals thereafter for $3 \mathrm{hr}$. The samples were centrifuged immediately and the plasma frozen at $-20^{\circ} \mathrm{C}$ for later analysis. Plasma theophylline concentrations were measured by a homogeneous enzyme immunoassay (EMITSyva, St Ives House, Maidenhead, Berkshire, England). In asthmatic patients the therapeutic range is $10-20 \mu \mathrm{g} / \mathrm{ml}$ (Mitenko and Ogilvie, 1973; Nicholson and Chick, 1973).

All studies were performed following an overnight fast, the patients receiving no medication on the morning of the study.

\section{Haemodynamic measurements}

A triple lumen thermister-tipped flotation balloon catheter was introduced through a subclavian vein and passed under fluoroscopic control into the pulmonary artery. Right atrial pressure (RAP), mean pulmonary artery wedge pressure (MPAWP) and pulmonary artery systolic and diastolic pressures were measured using Bell and Howell transducers and displayed on a Roche 144 monitor. The zero point was set at the sternal angle with the patient positioned at $45^{\circ}$. Cardiac output (CO) was measured by thermodilution (Ganz and Swan, 1972). Measurements were made in triplicate and the mean was calculated. Systemic arterial pressure (SAP) was measured with an indwelling radial artery catheter in two patients and sphygmomanometrically in the remainder. Heart rate was counted from the ECG monitor over a period of one min at the start of each set of observations.

The study consisted of a 30-min control period followed by a 3-hr period in which the effects of the drug were observed. Two sets of measurements were made in the control period, 30 min apart (time- 30 and $0 \mathrm{~min}$ ). The drug was then given, and measurements repeated after $30,60,90,120$, 150 and $180 \mathrm{~min}$.

Mean pulmonary artery pressure (MPAP) and MPAWP were obtained by electronic integration. Mean SAP (MSAP) was obtained by electronic integration in the two patients who had an indwelling arterial catheter. In the remaining seven patients it was calculated from the formula

$$
\operatorname{MSAP}=\frac{S-D}{3}+D,
$$

where $S=$ systolic pressure and $D=$ diastolic pressure.

Left ventricular filling pressure (LVFP) was taken to be equal to MPAWP, but in four patients in whom this could not be measured accurately it was taken to be equal to pulmonary artery diastolic pressure (Jenkins, Bradley and Branthwaite, 1970).

The following formulae were also used: cardiac index $(\mathrm{CI}) 1 / \mathrm{min} / \mathrm{m}^{2}=(\mathrm{CO}) \div$ body surface area (BSA); stroke volume index (SVI) $\mathrm{ml} / \mathrm{m}^{2}=$ stroke volume $\div$ BSA. Left ventricular stroke work index $($ LVSWI $) \mathrm{g} / \mathrm{m}^{2}=($ MSAP - LVFP $) \times$ SVI $\times 0.0136$.

Systemic vascular resistance (SVR) dyne $\mathrm{s} \mathrm{cm}^{-5}$ $=$ MSAP $\div$ CO. Statistical analysis was by the paired Student's $t$ test.

Cardiac rhythm was monitored oscillographically in all the patients. In seven patients, continuous recordings were also made on electromagnetic tape (Avionics, Electrocardiocorder, model 425) for the $3.5 \mathrm{hr}$ of the study. Trained technicians analysed the tapes (Avionics, Electrocardioscanner, Model $660 \mathrm{~A})$ and the recordings were subsequently checked by two physicians.

\section{Results}

During the 30-min control period there were no statistically significant changes in any of the haemodynamic indices, indicating that the patients were in a steady state (Fig. 1, Table 2).

The mean control CI was $1.75( \pm 0.14$ s.e. mean $)$ $1 / \mathrm{min} / \mathrm{m}^{2}$ and it rose following the administration of theophylline to a maximum of $2.04( \pm 0.11) \mathrm{l} / \mathrm{min} / \mathrm{m}^{2}$ at $180 \mathrm{~min}(P<0.02)$. The increase in $\mathrm{CI}$ was seen in 7 of the 9 patients, the maximum rises ranging from $9 \%$ to $40 \%$. Absence of response in one patient was attributed to poor drug absorption, evidenced by subtherapeutic plasma theophylline concentrations. Failure of response in the other patient may have been due to extensive myocardial hypokinesia (ejection fraction $7 \%$ ).

SVI increased from a mean control value of 20 $( \pm 2 \cdot 5)$ to $21( \pm 2 \cdot 1) \mathrm{ml} / \mathrm{m}^{2}$ at $120 \mathrm{~min}(P<0 \cdot 05)$.

LVFP fell from a mean control of $27( \pm 2.4)$ to $22( \pm 1 \cdot 5) \mathrm{mmHg}$ at $120 \mathrm{~min}(P<0.01)$. LVFP fell in all 9 patients, the fall ranging from 3 to 17 mmHg.

RAP fell from a mean control value of $5( \pm 1 \cdot 8)$ to $3( \pm 2) \mathrm{mmHg}$ at $90 \mathrm{~min}(P<0.05)$.

LVSWI rose from a mean control value of 15 $( \pm 3.2)$ to $19( \pm 2.9) \mathrm{g} / \mathrm{m}^{2}$ at $120 \mathrm{~min}(P<0.01)$.

MSAP rose from a mean control value of $80( \pm 3)$ to $86( \pm 3.5) \mathrm{mmHg}$ at $150 \mathrm{~min}(P<0.05)$.

There were no statistically significant changes in heart rate, MPAP or SVR during the study.

One patient became nauseated and another 
vomited following administration of the drug. These two patients had the highest peak plasma theophylline levels ( 20 and $25 \mu \mathrm{g} / \mathrm{ml}$ ). No other symptoms could be elicited.
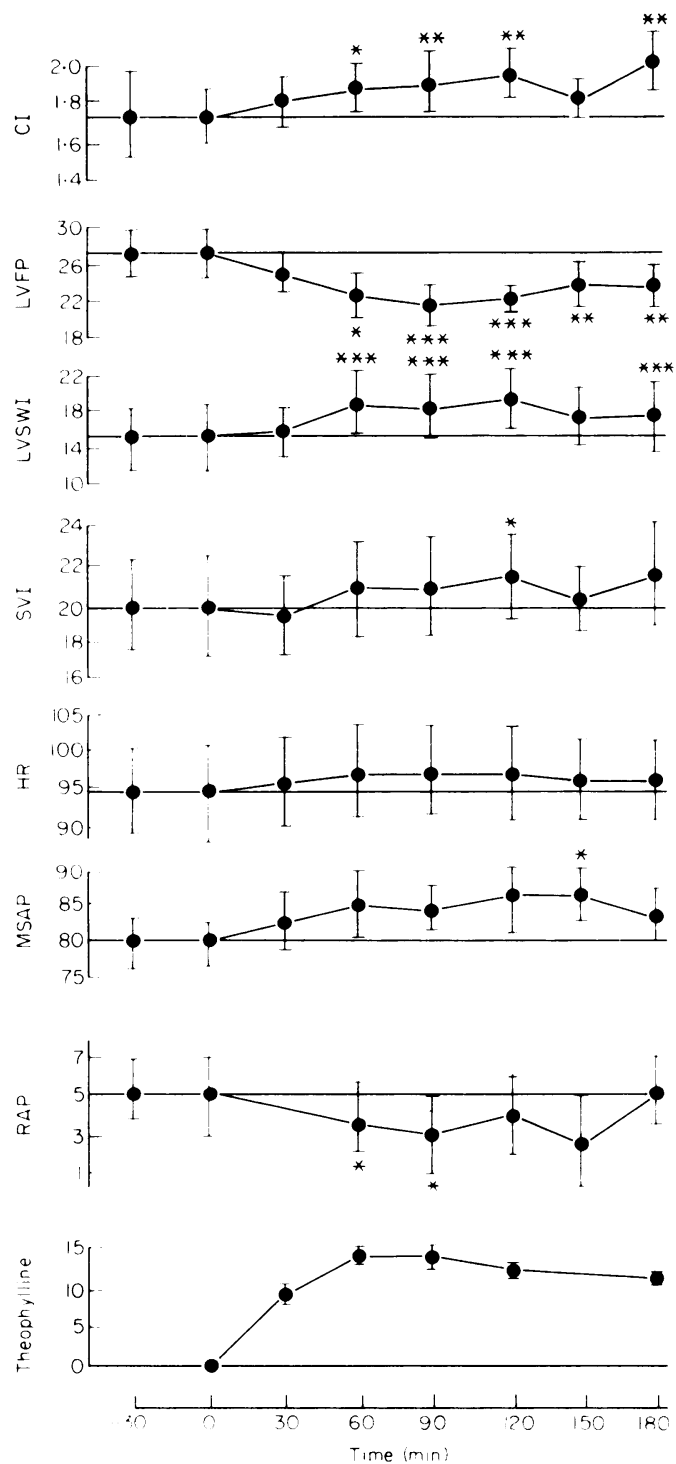

FIG. 1. Haemodynamic variables and plasma theophylline concentrations. Theophylline choline $600 \mathrm{mg}$ given orally at time $0 . \mathrm{CI}=$ cardiac index $\left(1 / \mathrm{min} / \mathrm{m}^{2}\right) ; \mathrm{LVFP}=$ left ventricular filling pressure $(\mathrm{mmHg}) ; \mathrm{LVSWI}=$ left ventricular stroke work index $\left(\mathrm{g} / \mathrm{m}^{2}\right) ; \mathrm{SVI}=$ stroke volume index $\left(\mathrm{ml} / \mathrm{m}^{2}\right) ; \mathrm{HR}=$ heart rate (beats $\left./ \mathrm{min}\right) ; \mathrm{MSAP}=$ mean systemic arterial pressure $(\mathrm{mmHg}) ; \mathrm{RAP}=$ right atrial pressure $(\mathrm{mmHg})$; theophylline $=$ plasma theophylline concentration $(\mu \mathrm{g} / \mathrm{ml})$. ${ }^{*} P<0.05 ;{ }^{* *} P<0.02 ;{ }^{* * *} P<0.01$. Comparisons are with mean control.
Seven patients had no change in their rhythm. One patient developed rate-related intraventricular conduction delay and another developed an episode of ventricular tachycardia (rate $120 / \mathrm{min}$ ) which terminated spontaneously. This patient had had episodes of ventricular tachycardia before the administration of theophylline. He also had the highest peak concentration of plasma theophylline, $25 \mu \mathrm{g} / \mathrm{ml}$. The arrhythmia occurred one hour after this peak was reached, at which time plasma theophylline concentration was $14.5 \mu \mathrm{g} / \mathrm{ml}$.

Plasma theophylline concentrations were measured in all nine patients. Absorption of theophylline was variable; the peak plasma concentrations were reached between 30 and 120 min following administration and ranged from 8 to $25 \mu \mathrm{g} / \mathrm{ml}$ (average $14 \mu \mathrm{g} / \mathrm{ml}$ at one hour). Side effects were only seen in the two patients who had plasma theophylline concentrations exceeding $19 \mu \mathrm{g} / \mathrm{ml}$. There were no correlations between peak plasma theophylline concentrations and the maximum changes in CI or LVFP.

\section{Discussion}

Intravenous theophylline and its derivatives were used for many years for the treatment of acute pulmonary oedema but the drug fell out of usê following the recognition of serious side effects, in particular tachyarrhythmia and vomiting. These side effects were probably due to drug overdose, as theophylline clearance is reduced in heart failure (Powell et al., 1978); when plasma theophylline concentrations are kept within the therapeutic range of $10-20 \mu \mathrm{g} / \mathrm{ml}$ side effects are rarely encountered (Mitenko and Ogilvie, 1973; Nicholson and Chick, 1973). The introduction of oral slow release preparations of theophylline and aminophylline has been an important development as they avoid the peaks and troughs of plasma theophylline that were seen with the former preparations (Jones, 1979). If the incidence of side effects is reduced these new formulations may become useful in the treatment of chronic heart failure refractory to diuretics. But before evaluating the clinical usefulness of the slow-release preparations it is important to assess the acute haemodynamic effects of a rapidly absorbed oral preparation.

The present results show that a single dose of theophylline choline given orally caused a significant increase in CI and reduction in LVFP and RAP. Most of the increase in $\mathrm{CO}$ was due to an increase in stroke volume, as heart rate did not change significantly. There were no significant changes in SVR but MSAP rose presumably as a result of the increased cardiac output. 
Theophylline exerts a positive inotropic effect on the cat papillary muscle (Marcus et al., 1972) and intravenous infusions of aminophylline exert a positive inotropic effect in patients undergoing cardiac catheterization for valvular disease (Murphy et al., 1968). As might be expected, $\mathrm{CO}$ is increased in those patients whose cardiac failure is due to myocardial rather than valvular pathology (Howarth et al., 1947; Parker et al., 1966; Murphy et al., 1968). The increase in CO and fall in LVFP in the present study can best be explained by a positive inotropic effect. Parker et al. (1966) suggested that peripheral vasodilatation may have a contributory effect on increasing cardiac output, but that mechanism cannot be invoked in this study as SVR did not fall. Howarth et al. (1947) examined the possibility that the increase in cardiac output may be due to venodilatation; they produced comparable reductions in RAP by congesting cuffs on the thighs and intravenous infusions of aminophylline, and found that the increase in cardiac output resulting from the latter was much greater. They concluded that aminophylline increases cardiac output by 'a direct stimulating action on the heart' rather than by venodilatation.

Two hypotheses, not mutually exclusive, have been proposed to explain the effect of theophylline on myocardial contractility. The first is by enhancing the calcium permeability of the sarcolemma (Scholz, $1971 \mathrm{a}, \mathrm{b})$, and the second by inhibition of phosphodiesterase, leading to an accumulation of cAMP intracellularly (Skelton, Levey and Epstein, 1970). The site of action of theophylline is probably on the sarcolemma rather than intracellularly (Bellemann and Scholz, 1974, 1975).

Side effects were only seen in two patients who had toxic plasma theophylline concentrations. It is not clear whether the development of an arrhythmia in one patient was due to theophylline administration, as this patient had had the arrhythmia before administration of the drug. In any case, a history of tachyarrhythmia may constitute a contra-indication to the administration of theophylline.

This study has shown that a rapidly absorbed oral theophylline preparation exerts a beneficial acute haemodynamic effect in chronic heart failure. Further studies will concentrate on a slow-release preparation in an attempt to determine whether the beneficial effects persist, and the ease with which plasma theophylline concentrations can be kept within the therapeutic range.

\section{Acknowledgments}

We thank Mrs I.L. Giles and Mrs M. Broomer for valuable technical assistance and Napp Laboratories Ltd for financial support.

\section{References}

BellemanN, P. \& Scholz, H. (1974) Relationship between theophylline uptake and inotropic effect in the guinea-pig heart. British Journal of Pharmacology, 52, 265.

Belleman, P. \& Scholz, H. (1975) Dissociation of theophylline uptake and inotropic effect in myocardial tissue: influence of temperature, $\mathrm{pH}$ and calcium. British Journal of Pharmacology, 54, 75.

Criteria Committee of the New York Heart Association, INC. (1964) Diseases of the Heart and Blood Vessels (Nomenclature and Criteria for Diagnosis), 6th edn, Little, Brown \& Company, Boston.

Fitchet, D.H., Marin Neto, J.A., OAKley, C.M. \& GoodWIN, J.F. (1979) Hydralazine in the management of left ventricular failure. American Journal of Cardiology, 44, 303.

Ganz, W. \& Swan, H.J.C. (1972) Measurement of blood flow by thermodilution. American Journal of Cardiology, $29,241$.

Howarth, S., McMichael, J. \& Sharpey-Schafer, E.P. (1947) The circulatory action of theophylline ethylene diamine. Clinical Science, 6, 125.

Jenkins, B.S., BRADley, R.D. \& BRanthWaite, M.A. (1970) Evaluation of pulmonary arterial end-diastolic pressure as an indirect estimate of left atrial mean pressure. Circulation, 42, 75 .

JoNES, R.W. (1979) Comparative pharmacokinetics of two theophylline derivatives in asthmatic patients. Journal of International Medical Research, 7 (suppl. 1), 16.

Marcus, M.L., Skelton, C.L., Grauer, L.E. \& Epstein, S.E. (1972) Effects of theophylline on myocardial mechanics. American Journal of Physiology, 222, 1361.

Mitenko, P.A. \& OGILvie, R.I. (1973) Rational intravenous doses of theophylline. New England Journal of Medicine, 289, 600.

MurPhy, G.W., Schreiner, B.F. \& YU, P.N. (1968) Effects of aminophylline on the pulmonary circulation and left ventricular performance in patients with valvular heart disease. Circulation, 37, 361.

Nicholson, D.P. \& CHICK, T.W. (1973) A re-evaluation of parenteral aminophylline. American Review of Respiratory Disease, 108, 241.

Parker, J.O., Kelly, G. \& West, R.O. (1966) Hemodynamic effects of aminophylline in heart failure. American Journal of Cardiology, 17, 232.

Powell, J.R., Vozeh, S., Hopewell, P., Costello, J., Sheiner, L.B., \& Riegelman, S. (1978) Theophylline disposition in acutely ill hospitalized patients. American Review of Respiratory Disease, 118, 229.

Scholz, H. (1971a) On the mechanism of the positive inotropic action of theophylline in mammalian cardiac muscle II. Effect of theophylline on uptake and release of ${ }^{45} \mathrm{Ca}$. Naunyn-Schmiedebergs Archiv für Pharmakologie, 271, 396.

ScHolz, H. (1971b) On the mechanism of the positive inotropic action of theophylline in mammalian cardiac muscle III. Effect of theophylline on contractile force and $\mathrm{Ca}$ dependent changes of membrane potential. NaunynSchmiedebergs Archiv fïr Pharmakologie, 271, 410.

SHARMA, B. \& GoodWIN, J.F. (1978) Beneficial effect of salbutamol on cardiac function in severe congestive cardiomyopathy. Circulation, 58, 449.

Skelton, C.L., Levey, G.S. \& Epstein, S.E. (1970). Positive inotropic effects of dibutyryl cyclic adenosine 3',5'monophosphate. Circulation Research, 26, 35.

Williams, D.O., Bommer, W.J., Miller, R.R., Amsterdam, E.A. \& MASON, D.T. (1977) Hemodynamic assessment of oral peripheral vasodilator therapy in chronic congestive heart failure: prolonged effectiveness of isosorbide dinitrate. American Journal of Cardiology, 39, 84. 